P0166

\title{
TOOL FOR ANALYSIS OF TUNNEL LIGHTING BASED ON VISUAL PERFORMANCE AND VISUAL COMFORT Dennis Corell et al.
}

DOI 10.25039/x46.2019.PO166

from

CIE x046:2019

Proceedings

of the

29th CIE SESSION

Washington D.C., USA, June 14 - 22, 2019

(DOI 10.25039/x46.2019)

The paper has been presented at the 29th CIE Session, Washington D.C., USA, June 14-22, 2019. It has not been peer-reviewed by CIE.

(C) CIE 2019

All rights reserved. Unless otherwise specified, no part of this publication may be reproduced or utilized in any form or by any means, electronic or mechanical, including photocopying and microfilm, without permission in writing from CIE Central Bureau at the address below. Any mention of organizations or products does not imply endorsement by the CIE.

This paper is made available open access for individual use. However, in all other cases all rights are reserved unless explicit permission is sought from and given by the CIE.

CIE Central Bureau

Babenbergerstrasse 9

A-1010 Vienna

Austria

Tel.: +4317143187

e-mail: ciecb@cie.co.at

www.cie.co.at 


\title{
TOOL FOR ANALYSIS OF TUNNEL LIGHTING BASED ON VISUAL PERFORMANCE AND VISUAL COMFORT
}

\author{
Corell, D.D. ${ }^{1}$, Jørgensen, A. ${ }^{2}$, Hafdell, P. ${ }^{3}$, Ekrias, A. ${ }^{4}$, Sørensen, K. ${ }^{5}$ \\ 1 Technical University of Denmark, Roskilde, DENMARK, ${ }^{2}$ Road Directorate, Oslo, NORWAY, \\ ${ }^{3}$ Trafikverket, Stockholm, SVERIGE, ${ }^{4}$ LiCon-AT Oy, Espoo, FINLAND, ${ }^{5}$ Johnson Consult, \\ Kgs. Lyngby, DENMARK \\ ddco@fotonik.dtu.dk
}

DOI 10.25039/x46.2019.PO166

\begin{abstract}
This study describes a method to derive a profile of the road surface luminance in long tunnels based on visual performance and visual comfort and its implementation in an excel file, which is freely available to anybody with an interest. The method presents an alternative approach to the dimensioning of tunnel lighting, compared with the method of CIE 88:2004 (CIE, 2004). As a minimum, the method can be used to reveal the influence of various parameters, such as the age of the driver. If accepted to a sufficient degree, the method can be used as a starting point for the design of tunnel lighting installations or modification of national standards.
\end{abstract}

Calculations show in particular a strong influence of the driving speed - or rather with the stopping distance associated with the driving speed. At low to medium driving speeds, the transition zones can be shorter than reflected by the standard curve from (CIE, 2004).

Keywords: Tunnel lighting, Visibility level, Visual performance, Visual comfort, Calculation tool

\section{Introduction}

CIE 88:2004 (CIE, 2004), supplies:

- Methods based on the visibility of a small object to determine the Lth value, which is the road surface luminance at the tunnel entrance.

- A standard curve for the road surface luminance through the threshold and transition zones.

Most national standards on tunnel lighting use this or similar approaches.

The standard curve is traditionally assumed to represent adaptation over 25 seconds of driving. The curve is based on old experiments.

More recent experiments carried out by Eran Aronson (Aronson, 2013) indicate that observers can adapt from high luminance levels of $6-8000 \mathrm{~cd} / \mathrm{m}^{2}$ down to low levels of $2 \mathrm{~cd} / \mathrm{m}^{2}$ in 5 seconds.

This may indicate that adaptation is so fast, that it is not the main issue to be concerned with. Accordingly, the $L_{\text {th }}$ value and the curve of the road surface luminance may be replaced by a profile of the road surface luminance based on visibility.

This paper presents a method, in which the profile of the road surface luminance is based on the visibility of a small object placed at the stopping distance in a range of locations from the tunnel entrance and well into the inner zone. The method does not include the exit zone.

The visibility is expressed by a minimum visibility level, VL of 5 . It is calculated in accordance with Werner Adrian (Adrian, 1989). The calculations include all factors, such as disability glare, drivers age and exposure time.

However, when taking only visibility into account, the profile may in some cases show a fast decrease that may cause visual discomfort. For this reason, a limit to the rate of the decrease is introduced as an additional criterion for visual comfort. 
This criterion is based on a statement by Duco Schreuder (Schreuder, D, 1987):

"After the threshold zone, the luminance may gradually decrease towards the tunnel interior in such a way that the light level is not below the (temporal) adaptation. Experiments have suggested that a reduction in luminance of a factor of 10 in about 2 of 3 seconds can be tolerated, although some discomfort may arise. The corresponding region is called the transition zone".

The visual comfort criterion is expressed as a minimum time of 5 seconds for a luminance decrease of a factor of 10 .

In order to obtain comparability to values traditionally used, two additional criteria are introduced, both are optional:

- The value of the road surface luminance of the interior zone, Lin.

- A maximum road surface luminance, normally acting only in the threshold zone.

The method has some additional input parameters that include the driving speed, the stopping distance, the transmittance of the windscreen and different sources of disability glare.

The results include a profile of the road surface luminance and a number of additional values.

The excel file can be used to analyse the influence of various parameters, such as the age of the driver or, if accepted to a sufficient degree, as a starting point for the design of a tunnel lighting installation.

The method is implemented in an excel file, there are no claims to any part of the method and the file is freely available to anybody with an interest.

\section{Method}

The method provides the profile of road surface luminance values that brings compliance with the relevant criteria mentioned below. This is done in a simulated drive, which is actually repeated a number of times so that the profile converges in an iterative process.

In a drive, the driver starts a location of one stopping distance in front of the tunnel, and moves in steps of one tenth of the stopping distance.

The first important criterion is that the driver is able to discriminate an object one stopping distance ahead with a minimum visibility level in circumstances defined by a number of input values. If lower/higher, the road surface luminance at the location of the object is raised / reduced. This is a visibility criterion.

A second criterion is that the road surface luminance value at a location must not be lower than a particular fraction of the value at the previous location. If too low, the value is raised in order to bring compliance with the criterion. This is a visual comfort criterion. When relevant, it overrules the visibility criterion causing a local raise of the visibility level.

The road surface luminance falls gradually towards a constant level $L_{\text {in }}$, which marks the start of the interior zone. The value of $L_{\text {in }}$ is determined by the visibility criterion, but can be replaced by a value entered as an input value. This causes a calculation of the actual visibility level which, in order to provide a smooth transition, is introduced internally already for the transition zone. This is an optional criterion for the luminance in the interior zone.

There is an additional criterion that the road surface luminance cannot exceed a certain maximum value, which is preset to $1000 \mathrm{~cd} / \mathrm{m}^{2}$. It has the simple effect to override the other criteria locally, and thereby cause a decrease of the local visibility level. This could happen in particular at locations in the threshold zone - notably the $L_{\text {th }}$ value at the tunnel entrance.

The procedure is governed by the above-mentioned criteria, and by several input values. These are shown in Figure 1, and introduced below. 


\begin{tabular}{|c|c|c|c|c|c|c|c|c|c|c|c|c|}
\hline \multicolumn{4}{|c|}{ Driving } & \multicolumn{2}{|c|}{ Visual task } & \multicolumn{3}{|c|}{ Disability glare } & \multicolumn{4}{|c|}{ Criteria } \\
\hline Design & Driver & Wind & Air & Size & Intrinsic & Daylight & Lighting & Other & Visibility & Time per & Road surf. & luminance \\
\hline speed & age & screen & transmit- & of object & Contrast & & installation & sources & Level & factor 10 & interior & maximum \\
\hline V & & trans. & tance & & of object & total Lseq & D & Lseg & $\mathrm{VL}$ & $\mathrm{t} 10$ & zone Lin & all zones \\
\hline $\mathrm{km} / \mathrm{h}$ & $23-75 y$ & $\%$ & $\%$ & $\mathrm{~m}$ & $\%$ & $\mathrm{~cd} / \mathrm{m} 2$ & & $\mathrm{~cd} / \mathrm{m} 2$ & & seconds & $\mathrm{cd}$ & $\mathrm{m} 2$ \\
\hline 80 & 60,0 & 80 & 100 & 0,2 & -68 & 300 & 0,1 & 0,25 & 5,00 & 5 & & 1000 \\
\hline
\end{tabular}

Figure 1 - Input Values

\subsection{Driving input values}

The design driving speed can be set to $60,70,80,90,100$ or $110 \mathrm{~km} / \mathrm{h}$. A choice of speed leads to a setting also of the stopping distance by reference to tables of national stopping distances. The actual table is selected by placement of a mark as shown in Figure 2. It is possible to insert stopping distances for other countries and to use these in the calculations.

\begin{tabular}{|c|c|c|c|c|c|c|c|}
\hline Mark a country or CIE & $\mathbf{x}$ & & & & & & \\
\hline Design speed & CIE 88:1990 & Denmark & Finland & Norway & Sweden & Country 1 & Country 2 \\
\hline $\mathrm{km} h$ & $\mathrm{~m}$ & $\mathrm{~m}$ & $\mathrm{~m}$ & $\mathrm{~m}$ & $\mathrm{~m}$ & $\mathrm{~m}$ & $\mathrm{~m}$ \\
\hline 60 & $\mathbf{6 0}$ & 66 & 75 & 60 & 55 & & \\
70 & 80 & 84 & 95 & 95 & 75 & & \\
80 & $\mathbf{1 0 0}$ & 103 & 120 & 115 & 97 & & \\
90 & 120 & 125 & 150 & 150 & 122 & & \\
100 & 140 & 148 & 180 & 190 & 151 & & \\
110 & $\mathbf{1 6 0}$ & 173 & 220 & 230 & 184 & & \\
\hline
\end{tabular}

Figure 2 - National tables of stopping distances.

The driver age is preset to 60 years in an attempt to represent the majority of drivers. Changes to lower or higher age values lead to fairly strong changes of road surface luminance levels as both the need for luminance and the sensitivity to disability glare increase with age.

The transmittance factors for the wind screen and the atmosphere have the same meaning as in CIE 88:2004 (CIE, 2004).

\subsection{Visual task input values}

In agreement with CIE 88:2004 (CIE, 2004), the object is a vertical square surface with a preset size of $0.2 \mathrm{~m}$ and a reflectance of 0.2 .

Also in agreement with CIE 88:2004, the intrinsic contrast is preset to $-68 \%$, as calculated for a lighting installation with a contrast revealing coefficient qc of 0,2 for symmetrical lighting. An alternative value is $-89 \%$ as calculated for a lighting installation with a contrast revealing coefficient qc of 0.6 for counter beam lighting.

A further input value is the exposure time of the object, which is set to 0.5 seconds. This is the only input value that is not readily available for modification.

\subsection{Disability glare input values}

Glare caused by daylight is indicated by a value of the total equivalent veiling luminance Lseq, which applies for the reference location of the driver one stopping distance in front of the tunnel. The value of $L_{\text {seq }}$ should include all the sources of veiling luminance mentioned in CIE 88:2004 (CIE, 2004): the equivalent veiling luminance from the surroundings to the tunnel, atmospheric veiling luminance and windscreen veiling luminance.

As the road surface luminance is calculated not only for the reference location of the driver, but also for a number of locations during his approach to the tunnel, it is necessary to provide fractions for the $L_{\text {seq }}$ value at the other locations. Therefore, a string of 11 fractions is supplied as shown in Table 1. 
Table 1 - Fractions for the total daylight $L_{\text {seq }}$ starting at the reference location and ending at the tunnel entrance

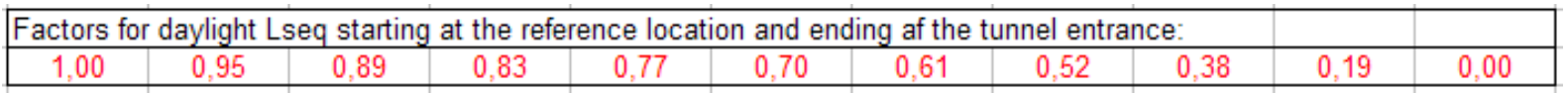

These fractions have been derived as averages for a number of tunnels in Norway (Sorensen, 2018)

The degree of glare D applies for the glare caused by the luminaires of the tunnel lighting installation and is used to determine the $L_{\text {seq }}$ value as $D$ times the local road surface luminance at the location of the driver.

Accordingly, this source of glare is applied only for locations of the driver inside of the tunnel, i.e. for the transition and interior zones. Reasonable values of $D$ can be evaluated by means of the maximum values of the threshold increment TI provided in EN 13201-2:2015 Road lighting - Part 2: Performance requirements. (EN, 2015)

Other glare sources may for instance be emergency escape lights or delineator lights. However, the main aim is the glare caused by headlamps on oncoming vehicles in dual traffic tunnels. Some typical $L_{\text {seq }}$ values are shown in Table 2, which has been copied from the report for COST action 331, Requirements for Horizontal Road Marking, European Communities 1999. (COST action 331)

Table 2 - Values of $L_{s e q}\left(\mathrm{~cd} / \mathrm{m}^{2}\right)$ for glare from headlamps of oncoming vehicles.

\begin{tabular}{|c|c|c|c|c|}
\hline \multirow{2}{*}{$\begin{array}{c}\text { Number of } \\
\text { oncoming } \\
\text { vehicles }\end{array}$} & \multicolumn{4}{|c|}{$\begin{array}{c}\text { Lateral separation to oncoming } \\
\text { vehicles }\end{array}$} \\
\cline { 2 - 5 } & $3,5 \mathrm{~m}$ & $7,0 \mathrm{~m}$ & $10,5 \mathrm{~m}$ & $14,0 \mathrm{~m}$ \\
\hline 1 & 0,098 & 0,024 & 0,011 & 0,006 \\
2 & 0,196 & 0,049 & 0,022 & 0,012 \\
3 & 0,294 & 0,073 & 0,033 & 0,018 \\
4 & 0,392 & 0,098 & 0,044 & 0,024 \\
5 & 0,490 & 0,122 & 0,054 & 0,031 \\
\hline
\end{tabular}

\subsection{Criteria input values}

The last group of input data relates to the criteria for the road surface luminance and includes:

- a minimum value of the visibility level VL,

- the maximum rate at which the road surface luminance can decrease, measured in seconds for a decrease of the luminance by a factor $10, t_{10}$,

- an optional value of the road surface luminance $L_{\text {in }}$ in the interior zone,

- a maximum value of the road surface luminance in all zones.

$\mathrm{VL}$ is the visibility level describing the visibility of the object. The minimum value for detecting the object is 1 , but in practice the value should be higher to ensure that a driver can detect objects in real situations. The value of VL has been preset to 5 . The VL value has a strong influence on the level of road surface luminance.

Another criterion concerns visual comfort and is the minimum time measured in seconds for a decrease of the luminance by a factor $10, t_{10}$. The preset value of 5 seconds seems to be relevant, but higher values could be considered. This criterion has an influence on the road surface luminance in the threshold and transition zones only.

$L_{\text {in }}$ is the luminance in the interior zone. If the input field is left empty, the above-mentioned VL criterion is applied in all the zones. This criterion has been introduced as an acceptance that the $L_{\text {in }}$ value is in practice often set on the basis of other criteria than just visibility.

The maximum value for the road surface luminance has been introduced because certain combinations of input values - for instance a high age of the observer, a high visibility level, a 
small object and a long stopping distance - can cause unrealistic high value of $L_{\text {th }}$. It is preferable to set a suitable maximum and then find other solutions - for instance assuming that drivers of high age are willing to reduce speed.

\section{Results}

The results of a calculation are a profile of the road surface luminance within the tunnel, a profile of $\mathrm{VL}$ and a number of additional values such as the initial luminance in the threshold zone $L_{\text {th }}$, the luminance in the interior zone $L_{\text {in }}$, the length of the transition zone, the duration of the drive in the transition zone and the k-factor. Using the input parameters from Figure 1 the results in Figure 3 can be obtained.

\begin{tabular}{|c|c|c|c|c|c|c|c|c|c|c|c|c|}
\hline \multicolumn{2}{|c|}{ Stopping distance } & \multicolumn{3}{|c|}{ Road surface luminance } & \multicolumn{4}{|c|}{ Visibility level VL } & \multicolumn{2}{|c|}{ Length of zones } & \multirow{3}{*}{$\begin{array}{c}\text { Time in } \\
\text { transition } \\
\text { zone }\end{array}$} & \multirow{3}{*}{$\begin{array}{c}\text { Lseq } \\
\text { surround } \\
300\end{array}$} \\
\hline \multirow[t]{2}{*}{ actual } & \multirow{2}{*}{$\begin{array}{l}\text { maximum } \\
\text { at VL level }\end{array}$} & \multirow[t]{2}{*}{ maximum } & \multirow{2}{*}{$\begin{array}{l}\text { Initial } \\
\text { Lth }\end{array}$} & \multirow{2}{*}{$\begin{array}{c}\text { Interior } \\
\text { Lin } \\
\end{array}$} & \multicolumn{2}{|c|}{ at tunnel entrance } & \multicolumn{2}{|c|}{ in interior zone } & \multirow[t]{2}{*}{ threshold } & \multirow[t]{2}{*}{ transition } & & \\
\hline & & & & & intended & actual & intended & actual & & & & \\
\hline \multicolumn{2}{|c|}{$\mathrm{m}$} & \multicolumn{3}{|c|}{$\mathrm{cd} / \mathrm{m} 2$} & \multicolumn{2}{|c|}{ agreement } & \multicolumn{2}{|c|}{ agreement } & \multicolumn{2}{|c|}{$\mathrm{m}$} & seconds & $\mathrm{k}$ factor \\
\hline 100 & 267 & 1000 & 124 & 0,73 & 5,00 & 5,00 & 5,00 & 5,00 & 100 & 224 & 10,08 & 0,019 \\
\hline
\end{tabular}
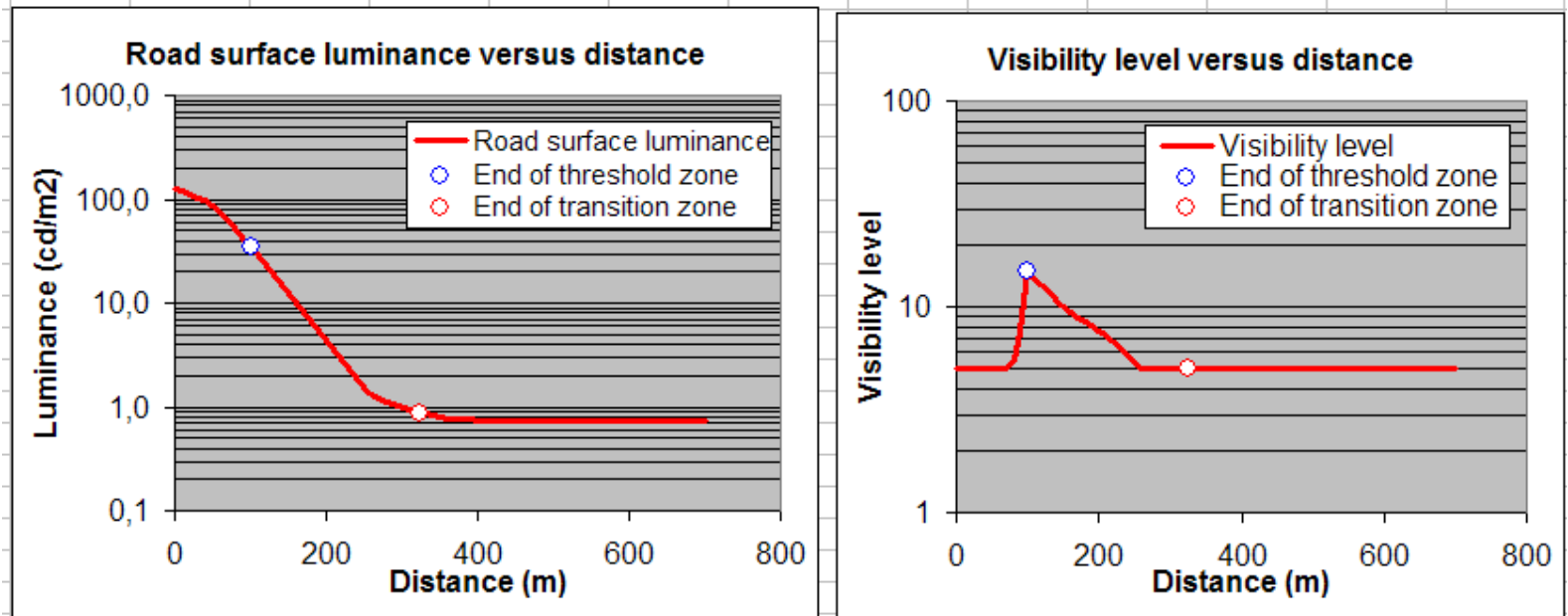

Figure 3 - Results of a calculation.

A separate box with additional input and results for a second driver of a different age and/or with a different driving speed may for instance be used to investigate the conditions for a driver of a high age, see Figure 4.

This box shows in particular that a driver of 75 years mostly has conditions as good as a driver of 60 years - if he reduces the speed by $10 \mathrm{~km} / \mathrm{h}$.

\begin{tabular}{|c|c|c|c|c|}
\hline Second & Second & Second & \multicolumn{2}{|c|}{ VL for second driver } \\
\hline driver & driver & stopping & reference & interior \\
\hline speed & age & distance & position & zone \\
\hline $\mathrm{km} / \mathrm{h}$ & $23-75 y$ & $\mathrm{~m}$ & & \\
\hline 70 & 75,0 & 80 & 4,99 & 83 \\
\hline
\end{tabular}

Figure 4 - Additional input and results for a second driver.

\section{Examples}

This section contains examples on the road surface luminance at different driving speeds. The stopping distances from CIE 88:1990 (CIE, 1990) have been used in the calculations.

Figure 5 shows luminance profiles for driving speeds of 60,80 and $110 \mathrm{~km} / \mathrm{h}$ with associated stopping distances of respectively 60,100 and $160 \mathrm{~m}$. The marks on the profiles indicate the ends of the threshold and transition zones. 
It is seen that the driving speed has a strong influence on the initial luminance in the threshold zone $L_{\text {th }}$, the length of the transition zone and the luminance in the interior zone $L_{\text {in. }}$. It is actually the stopping distances associated with the driving speeds, not the driving speeds themselves, which have this strong influence on the results. Accordingly, Figure 5 can be understood as providing the influence of stopping distances of 60,100 and $160 \mathrm{~m}$.

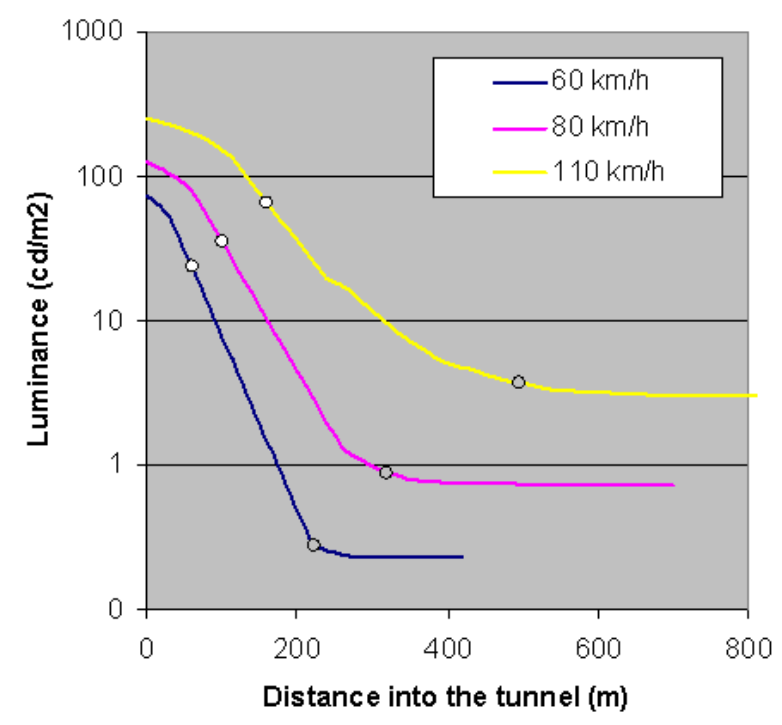

Figure 5 - Influence for different driving speeds.

\section{Conclusions}

A method to derive a profile of the road surface luminance based on visual performance and visual comfort has been established and implemented in an excel file. The method presents an alternative approach to the dimensioning of tunnel lighting, compared with the method of CIE 88:2004 (CIE, 2004) that involves calculation of a single road surface luminance at the tunnel entrance and use of a standard relative curve for all other locations in the tunnel.

As a minimum, the method can be used to reveal the influence of various parameters, such as the age of the driver. If accepted to a sufficient degree, the method can be used as a starting point for the design of tunnel lighting installations or modification of national standards.

Calculations show in particular a strong influence of the driving speed - or rather with the stopping distance associated with the driving speed. At low to medium driving speeds, the transition zones can be shorter than reflected by the standard curve.

The method is implemented in an excel file that is freely available. The excel file has not necessarily found its final form and can be adapted to specific applications and other input data.

\section{References}

ADRIAN, W., 1989. Visibility of Targets. Transp. Res. Rec. 39-45.

ARONSON, E., 2013. Research project: Visual adaptation for tunnel entrance, Final report. KTH Vetensk. Och Konst.

CIE, 2004. CIE 88:2004 "Guide for the Lighting of Road Tunnels and Underpasses 2ND ED.".

CIE, 1990. CIE 88:1990 "Guide for the Lighting of Road Tunnels and Underpasses."

EN, 2015. EN 13201-2:2015, "Road lighting - Part 2: Performance requirements."

SCHREUDER, D, A., 1987. The Lighting of traffic tunnels. Shanghai Assoc. Sci. Technol. 
Corell, D.D. TOOL FOR ANALYSIS OF TUNNEL LIGHTING BASED ON VISUAL PERFORMANCE AND VISUAL ...

SORENSEN, K., 2018. Values of L20 and Lseq for tunnels in Norway.

COST action 331, Requirements for Horizontal Road Marking, European Communities 1999 